\title{
The STAFF-DWP wave instrument on the DSP equatorial spacecraft: description and first results
}

\author{
N. Cornilleau-Wehrlin ${ }^{1}$, H. St. C. Alleyne ${ }^{2}$, K. H. Yearby ${ }^{2}$, B. de la Porte de Vaux ${ }^{1}$, A. Meyer ${ }^{1}$, O. Santolík ${ }^{3}$, \\ M. Parrot ${ }^{4}$, G. Belmont ${ }^{1}$, L. Rezeau ${ }^{5}$, O. Le Contel ${ }^{1}$, A. Roux ${ }^{1}$, D. Attié ${ }^{1}$, P. Robert ${ }^{1}$, V. Bouzid ${ }^{1}$, D. Herment ${ }^{1}$, and \\ J. $\mathrm{Cao}^{6}$ \\ ${ }^{1}$ CETP/IPSL, 10-12 Ave de l'Europe, 78140 Vélizy, France \\ ${ }^{2}$ University of Sheffield, Mappin Street, Sheffield, S1 3JD, UK \\ ${ }^{3}$ Faculty of Mathematics and Physics, V Holesovickach 2, CZ-180 00 PRAHA 8, Czech Republic \\ ${ }^{4}$ LPCE, 3A Av. de la Recherche Scientifique, 45071 Orléans Cedex 2, France \\ ${ }^{5}$ CETP/IPSL/UPMC, 10-12 Av. de l'Europe, 78140 Vélizy, France \\ ${ }^{6}$ CSSAR, Chinese Academy of Sciences, No 1, Nan Er Tiao, Zhong Guan Cun, Haidian District 100080, Beijing, People's \\ Republic of China
}

Received: 17 February 2005 - Revised: 8 July 2005 - Accepted: 22 August 2005 - Published: 8 November 2005

Part of Special Issue "Double Star - First Results"

\begin{abstract}
The STAFF-DWP wave instrument on board the equatorial spacecraft (TC1) of the Double Star Project consists of a combination of 2 instruments which are a heritage of the Cluster mission: the Spatio-Temporal Analysis of Field Fluctuations (STAFF) experiment and the Digital Wave-Processing experiment (DWP). On DSP-TC1 STAFF consists of a three-axis search coil magnetometer, used to measure magnetic fluctuations at frequencies up to $4 \mathrm{kHz}$ and a waveform unit, up to $10 \mathrm{~Hz}$, plus snapshots up to $180 \mathrm{~Hz}$. DWP provides several onboard analysis tools: a complex FFT to fully characterise electromagnetic waves in the frequency range $10 \mathrm{~Hz}-4 \mathrm{kHz}$, a particle correlator linked to the PEACE electron experiment, and compression of the STAFF waveform data. The complementary Cluster and TC1 orbits, together with the similarity of the instruments, permits new multi-point studies. The first results show the capabilities of the experiment, with examples in the different regions of the magnetosphere-solar wind system that have been encountered by DSP-TC1 at the beginning of its operational phase. An overview of the different kinds of electromagnetic waves observed on the dayside from perigee to apogee is given, including the different whistler mode waves (hiss, chorus, lion roars) and broad-band ULF emissions. The polarisation and propagation characteristics of intense waves in the vicinity of a bow shock crossing are analysed using the dedicated PRASSADCO tool, giving results compatible with previous studies: the broad-band ULF waves consist of a superimposition of different wave modes, whereas the magnetosheath lion roars are right-handed and propagate close to the magnetic field. An example of a combined Cluster DSP-TC1
\end{abstract}

Correspondence to: N. Cornilleau-Wehrlin

(nicole.cornilleau@cetp.ipsl.fr) magnetopause crossing is given. This first case study shows that the ULF wave power intensity is higher at low latitude (DSP) than at high latitude (Cluster). On the nightside in the tail, a first wave event comparison - in a rather quiet time interval - is shown. It opens the doors to future studies, such as event timing during substorms, to possibly determine their onset location.

Keywords. Space Plasma Physics (Instruments and techniques; Waves and instabilities) - Magnetospheric Physics (Solar wind-magnetosphere interactions)

\section{Introduction}

Double Star is the first Chinese magnetospheric mission, which, in co-operation with the European Space Agency, comprises 2 spacecraft that house some of the spare scientific instrument models of the ESA Cluster project. The Double Star orbits are such that they are complementary to those of Cluster and permit comparisons between both missions, which are greatly facilitated by similar instruments being mounted on the different satellites. Such is the case of the wave experiment on board TC1, the equatorial spacecraft of the Double Star Project (DSP). The combined STAFF-DWP wave experiment mainly consists of the spares of the Cluster Spatio-Temporal Analysis of Field Fluctuations (STAFF) experiment and of the Cluster Digital Wave-Processing experiment (DWP).

The main scientific objectives are to study the thin layers of the interaction regions between the solar wind and the Earth's magnetosphere and to understand the trigger mechanisms of magnetospheric substorms. Within these regions, 

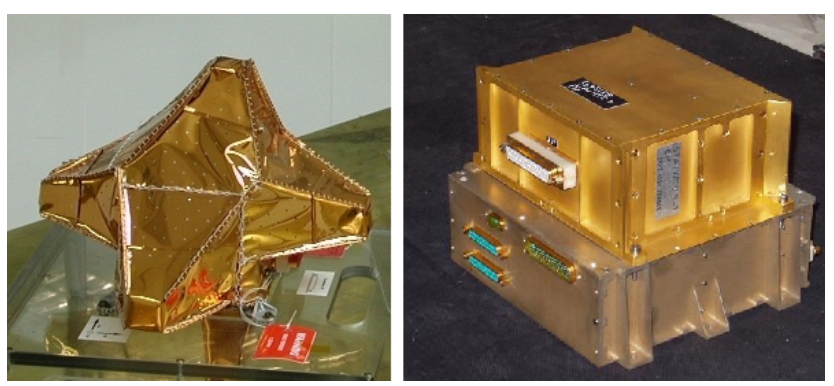

Fig. 1. Main elements of the STAFF-DWP experiment, at test. On the left: picture of the three-axis search coil magnetometer with its thermal blanket. On the right, the electronic box: on the bottom is the DWP box, on top of which is the magnetic waveform unit (MWF).

waves are of particular importance because, in the absence of collisions, they provide the effective coupling between particles of the same and of different species, and give rise to the anomalous transport. The understanding of the basic physics of these regions is facilitated by a comprehension of the wave-particle interactions therein, and their consequences for the various particle populations present, as well as for the link between small-scale and large-scale physical processes.

Whereas the study of physical processes in 3-D is performed thanks to the four Cluster spacecraft, enabling one to separate spatial and temporal effects, the complementary orbits of Cluster and DSP permits other studies. The TC1 spacecraft has its apogee at $13.3 R_{E}$ (Earth radii) and an inclination of $28.5^{\circ}$, whereas Cluster has a polar orbit with an apogee of $19.6 R_{E}$, both apogees being at the same local time. This, for example, allows for the study of the influence of latitude on the rate of penetration of the solar wind plasma into the magnetosphere at the magnetopause or to study in the tail the location of the substorm triggering region.

After a description of the STAFF-DWP experiment, some examples of first results are given.

\section{Instrument characteristics}

The STAFF-DWP DSP TC1 wave experiment consists of the Search Coil antenna, pre-amplifier, Magnetic Wave Form unit (MWF), and power supply provided by CETP, and the Digital Wave Processor provided by the University of Sheffield. The three first elements are spares of the Cluster STAFF experiment (Cornilleau-Wehrlin et al., 1997, 2003), the power supply is a spare of the Cluster WEC experiment (Pedersen et al., 1997) and the Digital Wave Processor is based on the Cluster DWP experiment (Woolliscroft et al., 1997). The main elements of STAFF-DWP are visible in Fig. 1, while in a clean room before integrating on the spacecraft. On the left is the three-axis search coil magnetometer with its thermal blanket, and on the right there is the electronics box. The electronics box is comprised of the DWP box, on top of which is the Magnetic Wave Form unit (MWF). The preamplifier and the power supply are not shown.

\subsection{STAFF search coils and preamplifiers}

The three-axis search coil magnetometer aims to measure magnetic fluctuations in the frequency range $0.1 \mathrm{~Hz}-4 \mathrm{kHz}$. The three mutually orthogonal sensors are mounted on a rigid boom that should have deployed away from the spacecraft body. Unfortunately, the STAFF antenna boom failed to deploy, which means interference from the spacecraft systems is very high. Even so, useful measurements can still be made, as will be shown later on.

Two sensors lie in the spin plane and the third one is parallel to the spacecraft spin axis. Figure 2 shows the position of the STAFF search coil antennas in stowed configuration. It gives the relationship between the search coil electrical axis $(B)$ and the spacecraft built axis $(S C)$ in the spin plane (left-hand side of the figure) and in the spacecraft X, Z plane (right-hand side). In the stowed configuration the relations between the antenna $(B)$ and spacecraft $(S C)$ axes are:

$B_{x}=S C_{z}, \quad B_{y}=-S C_{y}, \quad B_{z}=S C_{x}$.

The asymmetry induced by the deployed FGM boom and the undeployed STAFF boom, makes a $5^{\circ}$ angle between the spin axis and the spacecraft $S C_{z}$ axis. Note that the name of the electrical STAFF axes and spacecraft build axes are not the same, in order to keep the Cluster names for STAFF. When the data are further processed for scientific data analysis and transformed into physical units, rotations are performed. Note that in particular, the axis parallel to the spacecraft axis z, $S C_{z}$, is then named $B_{z}$.

The three sensors are identical. Each one consists of a high permeability core embedded inside two solenoids. The main winding has a very large number of turns mounted in separate sections. The frequency response of the sensor is flattened in the frequency range $40-4000 \mathrm{~Hz}$ by a secondary winding used to introduce flux feedback. The search coils are designed so as to minimise their sensitivity to electric fields.

Three preamplifiers are mounted in an electrical unit, located on the spacecraft deck. These are the spare models from Cluster, using hybrid technology, which has the advantage of including protection against radiation and the possibility, although not used on DSP, of thermal control. The low-power-consumption preamplifiers have a low-noise input stage and high-input impedance, since they are connected to the magnetic sensors which are characterised by a low DC resistance and very high impedance in the vicinity of the resonant frequency. The dynamic range of the preamplifiers is about $100 \mathrm{~dB}$, which allows weak signals to be measured in the presence of the large voltage induced by the rotation of the spacecraft in the DC magnetic field. With respect to Cluster, a slight modification has been applied to the DSP preamplifiers, in order to minimise the saturation due to the spin signal, as the DSP perigee is much lower than that of Cluster. A filter has been added in front of the preamplifiers input. The signal is then reduced by $15 \mathrm{~dB}$ more at $0.25 \mathrm{~Hz}$ (the spin rate is $4 \mathrm{~s}$ ), to keep a compromise between the part of 


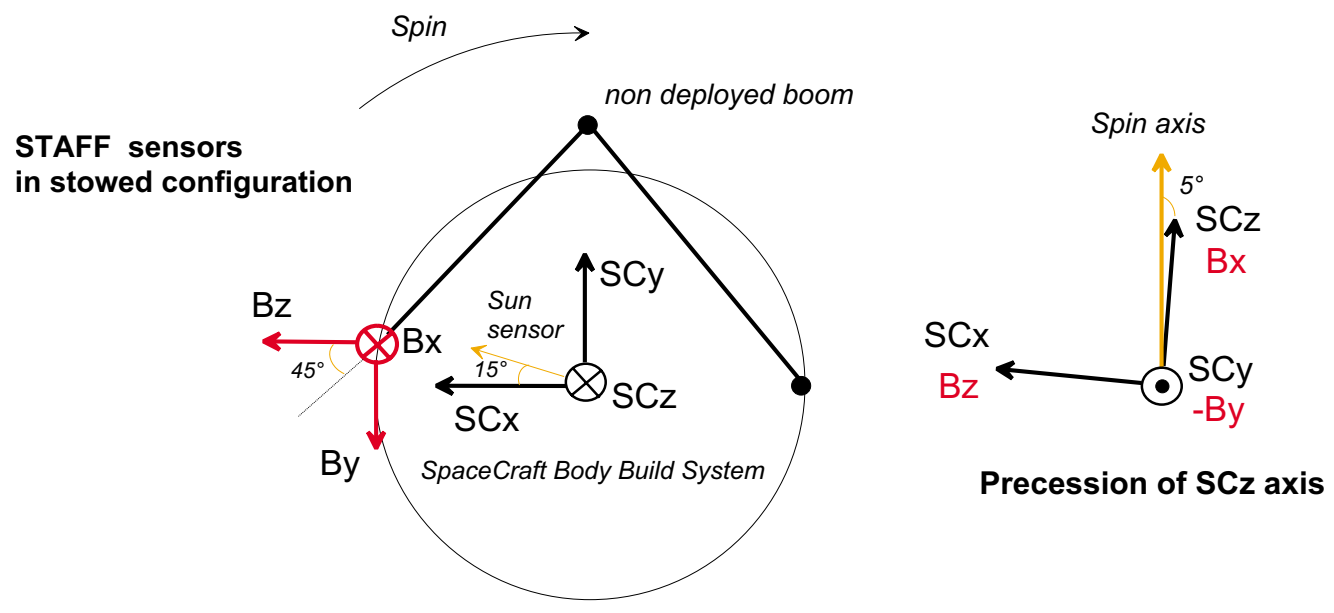

Fig. 2. Relationship between STAFF search coil electrical axis $(B)$, in the present stowed configuration, and the spacecraft built axis $(S C)$. At left: in the spin plane; at right: in the spacecraft $\mathrm{X}, \mathrm{Z}$ plane, perpendicular to the spin plane.

\section{STAFF Search Coils}
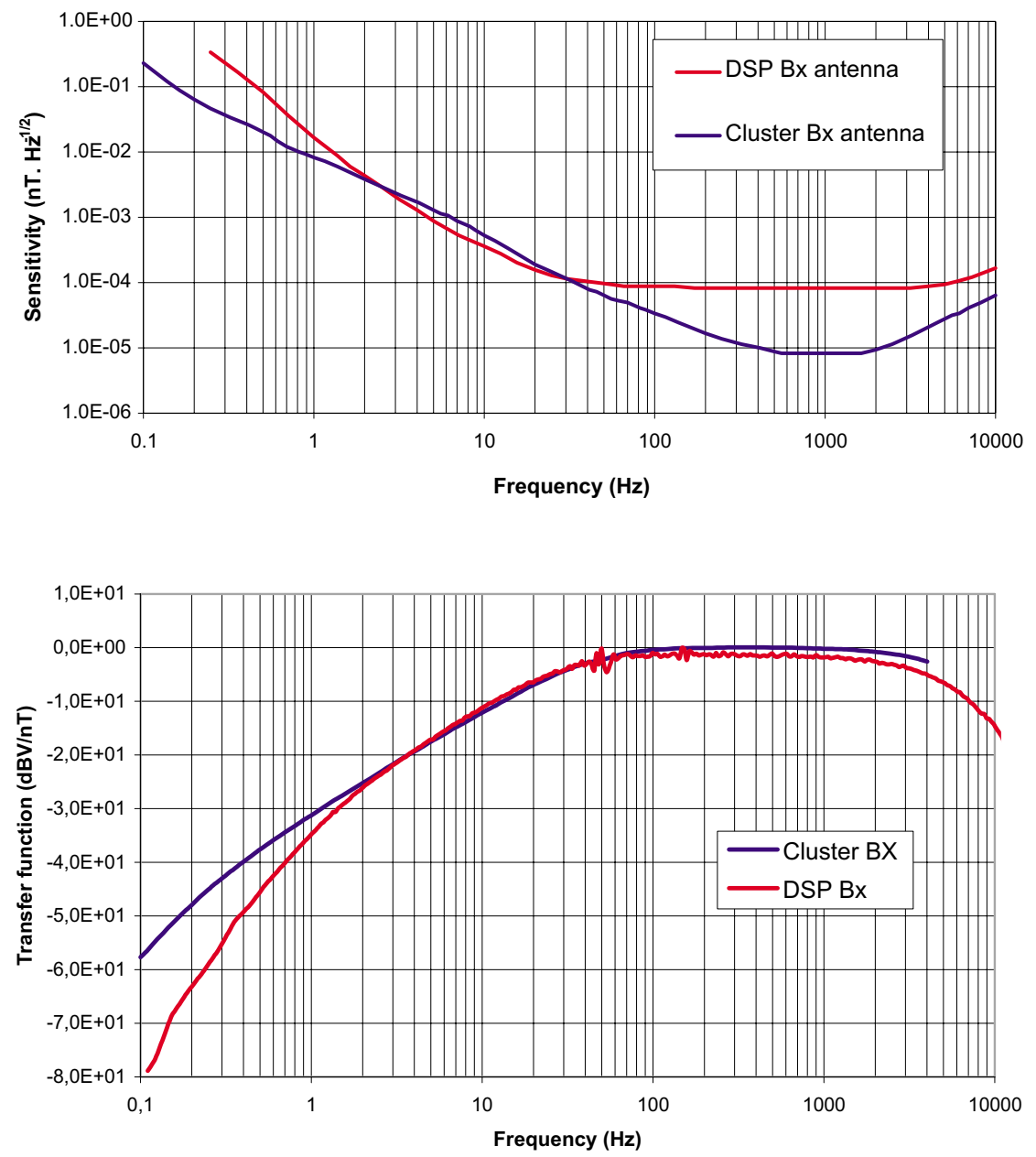

Fig. 3. The DSP TC1 sensitivity and transfer function of the $B_{x}$ component of the triaxial search coils of the STAFF experiment in red. For comparison the same for Cluster is drawn in blue. A filtering at the spin frequency has been added at the input of DSP preamplifiers, to take into account the strongest field at perigee, with respect to Cluster. 


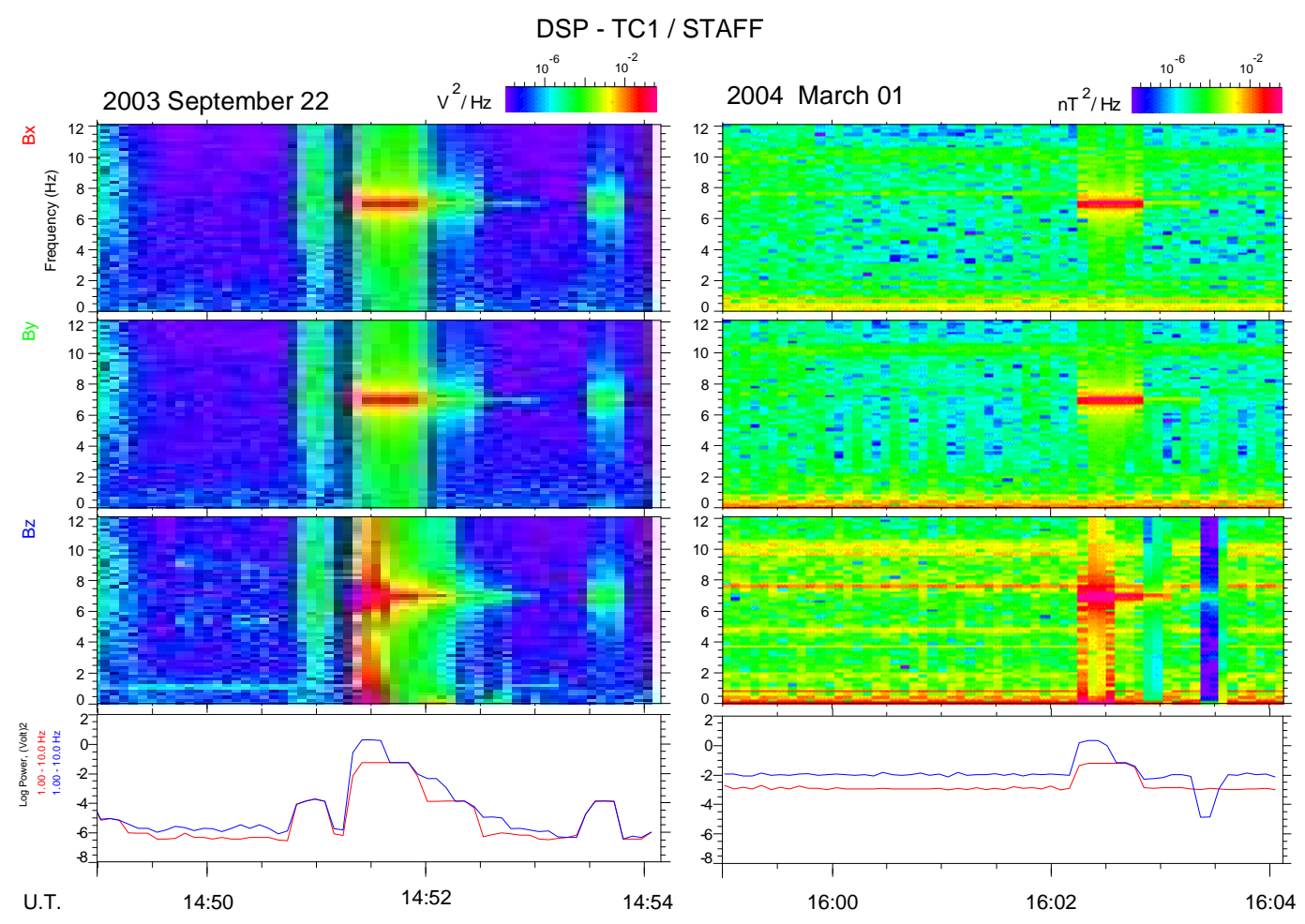

Fig. 4. Dynamic spectra in the $0.1-12 \mathrm{~Hz}$ frequency range for the 3 components, in telemetry units during calibration sequences. The bottom panel gives the integrated power of the signal in the $1-10 \mathrm{~Hz}$ frequency range for $B_{x}$ (in red) an $B_{z}$ (in blue) components for comparison, on the left-hand side is the result of a calibration on the ground, the antennas being in a $\mu$ metal box, and on the right-hand side in flight on 1 March 2004. It shows that despite the interferences due to the nondeployment of the STAFF boom, the experiment functions properly and provides meaningful scientific results. On the bottom panels, one can see that the power corresponding to the strongest calibration signals are identical, when above the interference level. The minimum signal on the right side for the $B_{z}$ component just before 16:03:30 UT corresponds to the direct access to the telemetry of the calibration signal, without going through the antennas, and its level is also identical in both cases (compare with data just after 14:52:30 UT on the left).

the orbit for which the search coil is not saturated and for the overall sensitivity of the experiment.

The experiment sensitivity and the transfer function are given in Fig. 3, together with Cluster STAFF sensitivity and transfer function for the sake of comparison. These measurements have been performed on the ground in a quiet site, Chambon la Forêt. One can see the slight difference induced by the DSP additional filter. The measured sensitivity is $1.5 \times 10^{-2} \mathrm{nT} \mathrm{Hz}^{-1 / 2}$ at $1 \mathrm{~Hz}, 3.0 \times 10^{-4} \mathrm{nT} \mathrm{Hz}^{-1 / 2}$ at $10 \mathrm{~Hz}$ and $10^{-4} \mathrm{nT} \mathrm{Hz}^{-1 / 2}$ between $30 \mathrm{~Hz}$ and $4 \mathrm{kHz}$.

The signal at the output of the preamplifiers goes to the Magnetic Wave Form analyser and to the Spectrum Analyser in the DWP box.

\subsection{The Magnetic Wave Form unit}

The Magnetic Wave Form unit (MWF) is comprised of two sets of low-pass filters, a waveform digitisation unit and a calibration unit.

The three magnetic components, $B_{x}, B_{y}, B_{z}$, at the output of the search coil preamplifier are passed through the lowpass anti-aliasing filters with a $-3 \mathrm{~dB}$ cut-off at $10 \mathrm{~Hz}$ for one set and at $180 \mathrm{~Hz}$ for the other set of filters. These filters are of the 7 th order, i.e. they have an attenuation of $42 \mathrm{~dB}$ per octave. They are stable to better than $1 \%$ in amplitude and $1^{\circ}$ in absolute phase.

The filtered signals are applied to three sample and hold devices, synchronised by the DWP experiment, then digitised and sent to the DWP experiment. The filtered signals are simultaneously sampled in a large dynamic range within a very short sampling time of about $10 \mu \mathrm{s}$, in order to guarantee a relative error of less than one degree at $180 \mathrm{~Hz}$ between the three components. The sampling rates are 25 and $450 \mathrm{~Hz}$, respectively.

The $96 \mathrm{~dB}$ dynamic range allowed by the 16-bit digitisation permits one to analyse simultaneously natural waves of a few $10^{-4} \mathrm{nT} \mathrm{Hz}^{1 / 2}$ and the large signal induced by the rotation of the spacecraft in the environmental DC field, up to about $10^{4} \mathrm{nT}$ at $0.25 \mathrm{~Hz}$. Unlike Cluster, data going through both sets of filters can be acquired simultaneously on DSP.

Owing to telemetry limitations, a reduction of the dynamic data range from 16 to 12 bits is performed inside DWP. The principle is to transmit the full 16-bit word at the beginning of each telemetry packet, and later the difference between the successive samples is coded on 12 bits in such a way that the dynamics of the experiment are preserved even at boundary 
DSP - STAFF-DWP : 2004/03/27

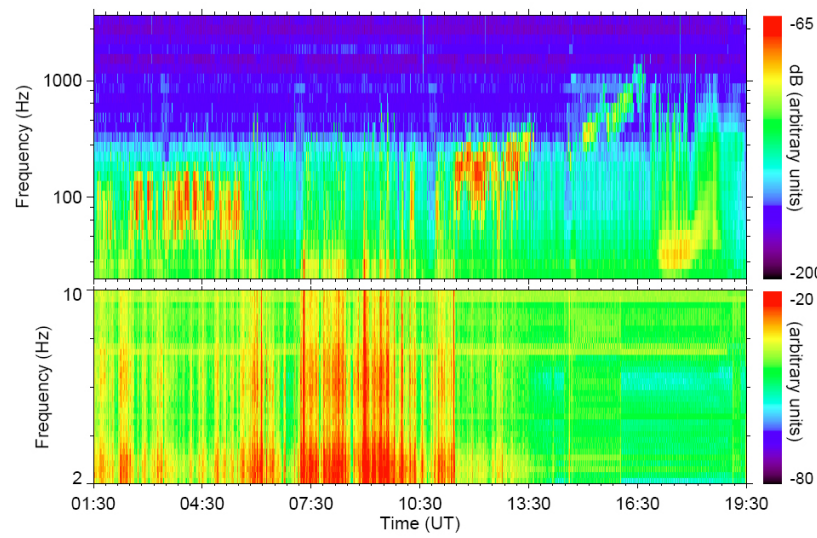

Fig. 5. Dynamic spectra of the less noisy component of the STAFF wave form data (from 2 to $10 \mathrm{~Hz}$ ) on the bottom and of the DWP spectrum analyzer (from $20 \mathrm{~Hz}$ to $4 \mathrm{kHz}$ ) on the top, for 27 March 2004, with a 1-min time resolution. Similar plots, for $3 \mathrm{~h}$ and for full orbit time periods, are available on DSDS web: http://edds02.iwf.oeaw.ac.at/dsdsweb-cgi/dsdsweb_pick.

crossings. Normally the differences are small enough so that this process occurs without a loss. There are 2 compression modes, one being called "normal" and the other called "backup", which is more conservative. Unlike on Cluster, in addition to the choice between either mode by telecommand, an option exists that automatically chooses the more appropriate compression mode. One can also choose by telecommand the "no compression" mode.

The MWF unit also generates an onboard calibration signal. The calibration signal is transmitted through the secondary winding of the antennas. Figure 4 gives a comparison between dynamic spectra of two calibration sequences: one on the ground (left-hand side) during integration on the spacecraft, with the search coils being in a $\mu$ metal box, and one in flight (right-hand side). One can see that the experiment itself works; in particular, the strongest calibration signal at $7 \mathrm{~Hz}$ is clearly visible, with the same intensity on the ground and in flight (see the bottom panels which give the integrated power in the 1 to $10 \mathrm{~Hz}$ frequency range, for $B_{x}$ in red and $B_{z}$ in blue). The comparison of the results of the two calibration sequences shows that above the noise level induced by the interferences, the intensity of the signal is correct. Moreover, one can see on the bottom spectra on the right side for the $B_{z}$ component, just before 16:03:30 UT, a weak background level, together with a calibration signal at $7 \mathrm{~Hz}$. This corresponds to a direct reception of the calibration signal, without going through the antenna, which allows verification that the intensity of the injected calibration signal itself has not changed. It is further evidence that the experiment is working correctly.

\subsection{Digital Wave Processor unit}

The Digital Wave Processor of the DSP Wave experiment is derived from the Cluster DWP experiment (Woolliscroft et al., 1997). The absence of electric field measurements on board DSP permits the replacement of some functions of the Cluster DWP, such as the data compression of Whisper data, by the functions of the Cluster Spectrum Analyser. DSP DWP has different functions: it performs on board spectrum analysis and MWF data compression, handles all telemetry and commanding for STAFF, and calculates the autocorrelations of electron counts received from PEACE (Fazakerley et al., 2005).

\subsubsection{The spectral analysis}

At higher frequencies, where the available telemetry does not permit acquisition of the waveform, an onboard Spectrum Analysis is performed by DWP. After the data pass through a low pass anti-alias filter, DWP digitises the 3 components of the analogue waveform at a $10-\mathrm{kHz}$ sampling rate. The filter is a 6th order Chebyshev, which provides at least $40-\mathrm{dB}$ rejection of aliases. There is also a simple 1st order high pass filter with a $10-\mathrm{Hz}$ cut-off frequency to reduce the amplitude of the $0.25 \mathrm{~Hz}$ spin frequency signal. A complex FFT is then calculated to obtain a spectral matrix in a format that is similar to that of Cluster after appropriate averages. The spectral matrix ( 3 power spectra, plus the cross-spectral phase between each component) is calculated at 27 frequencies between $20 \mathrm{~Hz}$ and $4 \mathrm{kHz}$, with a $1 \mathrm{~s}$ time resolution. Each component is given to 8 bits, which provides an average of $3 / 8 \mathrm{~dB}$ amplitude resolution, and $1.4 \mathrm{deg}$ in phase. This function of DWP differs from Cluster, where the STAFF experiment has its own dedicated spectrum analyser.

The spectrum analyser data may be processed on the ground to minimise the interference resulting from the nondeployment of the antenna boom. This is done by rejecting spectra acquired when large interference spikes occur, and by combining the signals from two axes of the antenna to synthesise a measurement in a direction where continuous interference is least. The optimum direction is adjusted as a function of frequency and spin phase. The data in Figs. 5 and 6 have been processed in this way. 


\section{STAFF/DWP 2004-03-27}

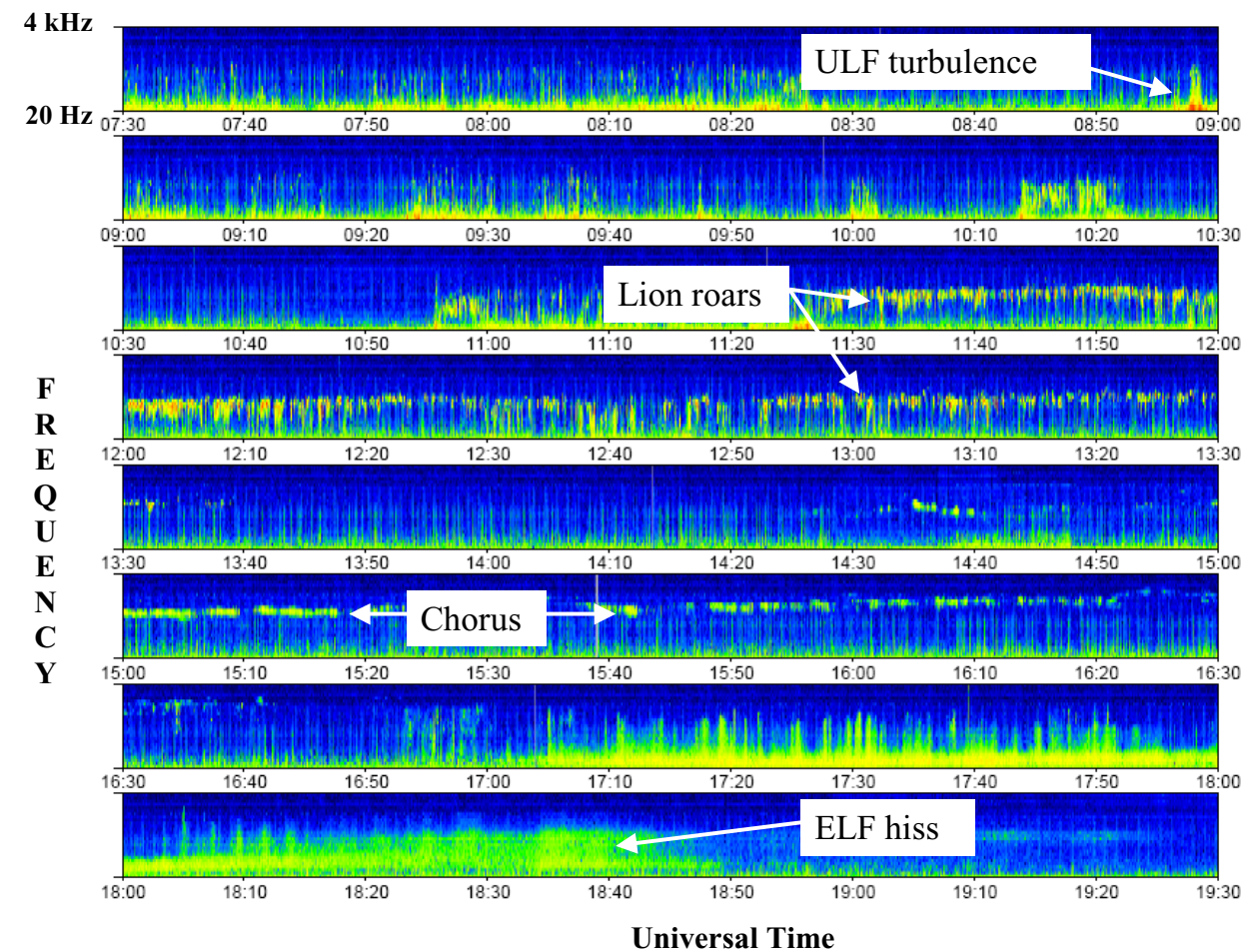

Fig. 6. Details of the spectrum analyser data for the same day as in Fig. 5, 27 March 2004, from 07:30 to 19:30 UT, with a 4-s time resolution, and a logarithmic frequency scale. This is an example of the different kinds of waves that can be observed on a dayside orbit of DSP TC1, here from the solar wind to perigee. ULF turbulence is observed at bow shock crossings, lion roars inside the magnetosheath, chorus and hiss in the inner magnetosphere.

\subsubsection{The electron autocorrelator}

DWP also performs autocorrelations of electron counts received by PEACE, the low and medium energy electron measurement experiment (Johnstone et al., 1997). PEACE is comprised of two complementary sensors on Cluster, each sensor of the spare model being implemented on the TC1 and TC2 (polar orbiting spacecraft of the Double Star mission) of DSP, respectively. On TC1, it is the HEEA (High Energy Electron Analyser) sensor which has an inter-experiment link to DWP. Thus, the correlator function of DWP is very similar on DSP as on Cluster.

The correlation is performed at one fixed energy and one energy that is stepped over a pre-defined range, at one step per spin. The correlator allows for the study of the time structure of the electron counts, in the frequency range 1.3 to $40 \mathrm{kHz}$. The autocorrelation may occur at a rate between one and 8 times per spin. Normally 4 times per spin is used.

The entire STAFF-DWP experiment is powered through the spare of the Cluster WEC power supply, which provides regulated power.

\subsection{Modes of operations}

On DSP there is only one telemetry rate. Nevertheless, different modes are possible and DWP may vary the combinations of the modes of the different parts of the STAFF-DWP experiment, in order to remain in the allocated telemetry. Examples of such mode combinations, which are more often used, are given in Table 1 .

A calibration is performed once a week. In spite of the nondeployment of the STAFF antennas' boom, the calibration examples provide the first evidence that the intensity of the measured wave events, when above the noise level, is significant. Before showing such results, let us comment on the interferences.

There are different sources of interferences. The first obvious ones come from the position of the antennas being stacked below the spacecraft. The interferences are payload and spacecraft mode of operation dependant, thus they vary often. This is why the search coils are usually housed on a boom away from the spacecraft. The $B_{y}$ component is the cleanest one (see Fig. 2). There are also interferences due to the solar panels. These ones are solar aspect angle dependant, especially when the solar panels are intermittently shadowed by the FGM boom. That is why corrections to the attitude of the spin axis to make this axis perpendicular to the ecliptic plane, to the extent possible, have been performed to reduce this source of interference. Such corrections of attitude have been done twice, on 17 February 2004 and on 13 July 2004. Just after the correction of attitude the data have much less interference and then data quality degrades 
progressively until the next manoeuvre, due to the natural evolution of the spacecraft attitude. Unfortunately, the third correction of attitude manoeuvre foreseen for 15 November 2004 could not be performed, as the Attitude Control Computer failed after the big storm at the beginning of November 2004. Nevertheless, the natural evolution of the position of the spin axis with time permits one to have the cleanest data during spring 2005. These interferences are mainly in the spin plane, at harmonics of the spin frequency $(0.25 \mathrm{~Hz})$. Globally, the interferences occur predominantly at low frequency, below $100 \mathrm{~Hz}$.

Taking the above considerations into account, it is not surprising that STAFF data are clean during eclipses. Moreover, during long eclipses, only STAFF-DWP and the magnetometer experiment FGM (Carr et al., 2005) are powered-on due to a power limitation, and thus the STAFF-DWP data are very clean, as will be shown later on. These long eclipses (up to about four hours) occur when DSP TC1 apogee is in the tail.

\section{First results}

In what follows we show that despite the nondeployment of the STAFF boom and the induced level of interference, some useful measurements are performed, in mainly two situations, either strong wave events, which is often the case on the dayside and in particular at boundary crossings, or during long eclipses in the tail. Unfortunately, during the long eclipses in the 2004 summer period, very few events were observed, out of which two examples will be shown below.

Besides the wave studies with particle and magnetometer measurements on board DSP itself, the main scientific objectives rely on comparisons with simultaneous measurements on board Cluster. The apogees of both missions are at the same local time, but the different maximum distances from the Earth and different orbit planes make the comparison very exciting. DSP TC1 offers a 5 th spacecraft to the resolution of the ambiguity of spatial and temporal effects. Among the scientific objectives to be fulfilled by the simultaneous measurements performed by DSP and Cluster are the role of magnetic fluctuations at the magnetopause and the substorm studies in the tail.

\subsection{Overview of wave events on the dayside}

An overview of the different waves encountered by DSP TC1 during a large part of an orbit (19h out of 27) is presented in Fig. 5 for 27 March 2004, when the orbit plane was at about 11:00 LT. In the top panel are plotted dynamic spectra calculated from the onboard spectrum analyser data in the $20 \mathrm{~Hz}-$ $4 \mathrm{kHz}$ frequency range. In the bottom panel of Fig. 5 are plotted the dynamic spectra of the wave component parallel to the spin axis in the $2-10-\mathrm{Hz}$ frequency range, calculated from the wave form data. This kind of plot is similar to the one produced at the DSDS public web site (http://edds02. iwf.oeaw.ac.at/dsdsweb-cgi/dsdsweb_pick). A strong wave activity can be seen, especially until 13:00 UT in both fre-
Table 1. The two main modes of operation of DSP-TC1 STAFFDWP experiment.

\begin{tabular}{ll}
\hline Mode 1 & bits/s \\
\hline Spectrum analyser (20 Hz-4 kHz) & 1606 \\
MWF 10-Hz mode (continuous, compressed, 12 bits) & 960 \\
MWF 180-Hz mode (1 s in 30-s duty cycle, compressed, 12 bits) & 560 \\
Correlator, 1 autocorrelation/spin & 216 \\
\hline Total & 3342 \\
\hline Mode 2 & bits/s \\
\hline Spectrum analyser (20 Hz-4 kHz) & 1344 \\
MWF 10-Hz mode (continuous, compressed, 12 bits) & 960 \\
MWF 180-Hz mode (off) & 0 \\
Correlator, 4 autocorrelations/spin & 896 \\
\hline Total & 3200 \\
\hline
\end{tabular}

quency ranges. By a visual inspection of the particle data on the DSDS web site, one can say that DSP was in the magnetosheath until 08:50 UT, then went back and forth many times in the solar wind until 11:30 UT, remained in the magnetosheath until about 14:00 UT, entering then the magnetosphere. The strongest broad-band ULF waves, the frequency spectra of which are turbulent-like, occur at shock crossings, but also ULF activity is present throughout the magnetosheath. Let us call in what follows this ULF broadband activity "ULF turbulence" (e.g. Saharaoui et al., 2004). At higher frequency there is also a lot of wave activity that changes in nature while DSP moves through the magnetosphere. This is seen in more detail in Fig. 6 which presents spectrum analyser data from 07:30 until 19:30 UT, with a time resolution of $4 \mathrm{~s}$ instead of $1 \mathrm{~min}$ in Fig. 5. One can see the high frequency part of electromagnetic turbulence at the bow shock crossing just before 09:00 UT, then as the spacecraft travels toward Earth in the magnetosheath, one can see quasi-monochromatic waves that are called lion roars (see, e.g. Smith and Tsurutani, 1976; Zhang et al., 1998; Baumjohann et al., 1999; Maksimovic et al., 2001). These are whistler mode waves known to occur in the magnetosheath, often in magnetic troughs but not always (Zang et al., 1998), usually linked to mirror modes (Tsurutani et al., 1982). More detailed analysis of lion roars seen by DSP is given in Yearby et al. (2005). After 14:30 UT, when DSP is in the magnetosphere, one can see two other types of whistler mode waves; first, chorus waves, whose frequency increases as DSP approaches the Earth and the magnetic field increases, as commonly seen with Cluster (Parrot et al., 2003a, b) and also DSP (Santolík et al., 2005). Then close to perigee, there is ELF hiss or equatorial noise, also called subLHR hiss (see, e.g. Russell et al., 1970; Santolík et al., 2002). While the observation of such waves in those regions is not new, it permits one to provide evidence that the experiment is able to give useful measurements. 


\section{DSP-TC1 STAFF-DWP 2004 April 05}

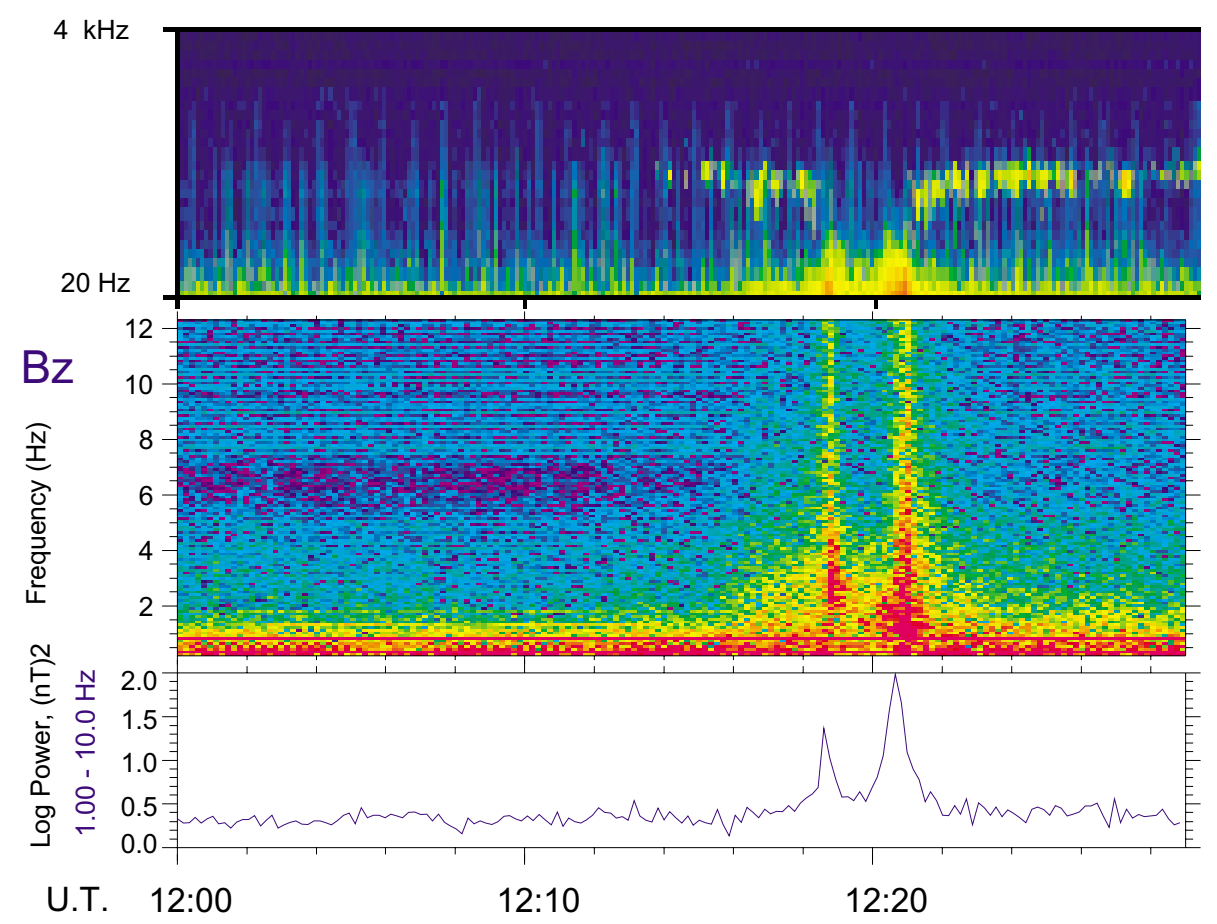

Fig. 7. Thirty minutes of STAFF data on 5 April 2004 when DSP was in the magnetosheath, at 09:30 LT, and went for a short excursion into the solar wind around 12:20 UT. From top to bottom are the dynamic spectra of total power from the spectrum analyzer $(20 \mathrm{~Hz}-4 \mathrm{kHz})$, the dynamic spectra for the $B_{z}$ component of the waveform data in the $0.5-12 \mathrm{~Hz}$ frequency range and the integrated power of the same component in the frequency range $1-10 \mathrm{~Hz}$. The turbulence associated with the shock crossings is seen by both parts of the experiment, up to about $70 \mathrm{~Hz}$, whereas on each side of the shock crossings, narrow band lion roars are clearly visible in the magnetosheath.

In what follows we give some examples of detailed measurements that open fields of future work.

\subsection{Characterisation of the waves in the vicinity of the bow shock - use of the PRASSADCO tool}

The $13.3 R_{E}$ apogee of the DSP equatorial spacecraft is very interesting for Earth bow shock studies, as it permits skimming the shock around noon local time at low latitude, whereas previous missions, such as ISEE 1 and 2, crossed the shock rather quickly at those local times. Presently, Cluster crosses the bow shock at higher latitude, which is very interesting for further Cluster and DSP TC1 data comparisons and the understanding of the physics of the bow shock.

An example of a double bow shock crossing is given in Fig. 7, when DSP left the magnetosheath to enter the solar wind for just $2 \mathrm{~min}$. The increase in the solar wind pressure, as observed at L1 by the ACE spacecraft during the preceding hour, explains that the shock crossed DSP. In the top panel is the dynamic spectrum of $30 \mathrm{~min}$ of Spectrum Analyser data, from 12:00 to 12:30 UT on 4 May 2004 when DSP was at about 10:00 LT. In the middle panel is the dynamic spectrum for the same time interval of MWF data for the $B_{z}$ component parallel to the spin axis, and in the bottom panel is given the ULF wave power integrated in the $1-10 \mathrm{~Hz}$ range. One can see that the ULF turbulence, which is characteristic of shock crossings (see, e.g. Figs. 4 and 9 of Cornilleau-Wehrlin et al., 2003, which show typical shock crossings seen by Cluster), is seen in both dynamic spectra, up to at least $70 \mathrm{~Hz}$. On each side of the shock, in the magnetosheath, a frequency band limited emission around $200 \mathrm{~Hz}$, called lion roars, is clearly visible in the upper panel. Lion roars are intense emissions that are often emitted above $100 \mathrm{~Hz}$ and thus do not suffer much from DSP interferences. That is why, for the time interval shown in Fig. 7, it has been possible to use a specific tool called PRASSADCO to characterise the waves. PRASSADCO (PRopagation Analysis of STAFF-SA Data with COherency tests) is a computer program designed to analyse multi-component measurements of electromagnetic waves. It implements a number of methods used to estimate polarisation and propagation parameters, such as degree of polarisation, sense and axes of polarisation ellipse, wave vector direction, Poynting vector, and refractive index (Santolík, 2003). The main purpose of PRASSADCO was first to facilitate scientific analysis of the spectral matrix obtained by the STAFF-SA (Spectrum Analyser) instruments on board the four Cluster satellites. Most of the results obtained with the Spectrum Analyser data of Cluster incorporate this tool (see, e.g. Parrot et al., 2003a; Santolík et al., 2002). PRASSADCO has been adapted to DSP data, in particular, it takes into account the position of the antennas as defined in Fig. 2. The 


\section{DSP - TC1 / STAFF-DWP 2004 April 05}

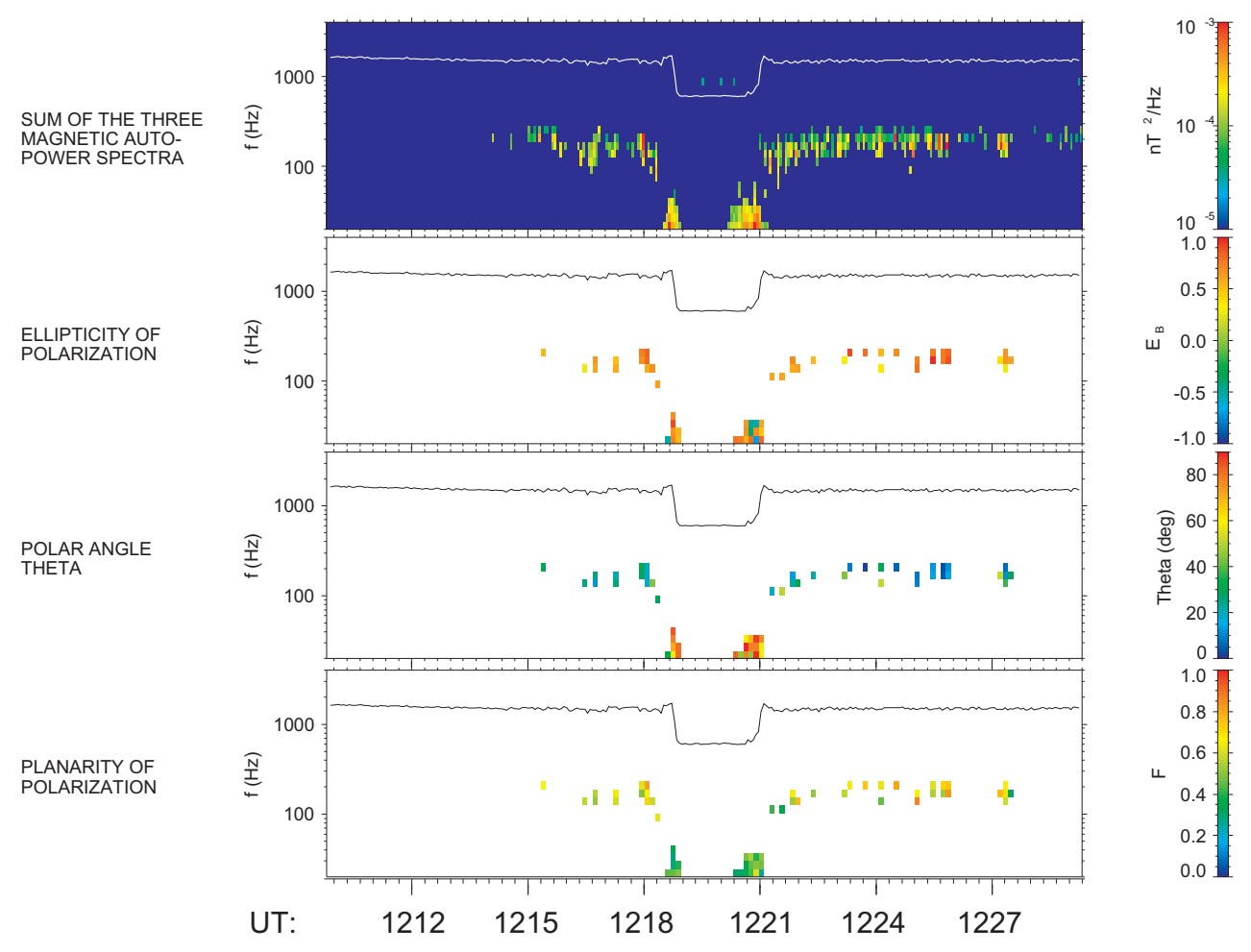

Fig. 8. Results of the PRASSADCO analysis of the same event as in Fig. 7. From top to bottom are plotted, in frequency-time the total power spectra, the ellipticity of polarization $(+1=$ circular right-handed , $0=$ linear, $-1=$ circular left-handed $)$, the polar angle $\theta(0=\mathrm{k}$ parallel to $\left.\mathrm{B}_{0}\right)$ and the planarity ( $1=$ plane waves). These wave polarization characteristics, color coded, are plotted only above a given wave power threshold. The electron gyrofrequency is over plotted on the dynamic spectra, showing clearly a reduced value in the solar wind. Whereas the polarization characteristics are confused for the turbulence at the shock, the lion roars are clearly right hand polarized, and propagate close to the magnetic field, $\theta<10^{\circ}$.

inputs of this software are, in addition to the DSP STAFFDWP raw data, the DSDS Prime Parameters of FGM, and the DSDS Summary Parameters of auxiliary data. The results can be represented in different visual and numerical formats. A similar program was used to analyse data of previous satellites (Santolík and Parrot, 1998, 1999; Santolík et al., 2001).

The results of the wave characterisation for $20 \mathrm{~min}$ of data that appear in the top panel of Fig. 7, around 12:20 UT, are presented in Fig. 8. The different panels, from top to bottom, give the total magnetic wave power dynamic spectra, then at the same frequency time scale, the ellipticity of polarisation, the polar angle theta and the planarity of polarisation. Those last three quantities are given only for frequency-time points corresponding to a magnetic power that is above some threshold to give only significant results. We can consider 2 different parts, first the ULF turbulence, then the lion roars. The planarity gives the significance of the results. Values close to zero mean that there is a mixture of different waves, whereas close to 1 it means that there is a plane wave. Then we see that the turbulence cannot be characterised, while it is closer to 1 for the lion roars. In the same way, there are different values of ellipticity for the turbulence and it is close to one, especially after 12:20 UT for the lion roars, which means that they are right-hand polarised waves, consistent with previous studies. Theta is small, between zero and $10^{\circ}$ for the lion roars, which is not inconsistent with previous studies, telling either that those waves propagate parallel to the main magnetic field (Baumjohan et al., 1999), or not always close to it (Zhang et al., 1998; Maksimovic et al., 2001). The study of this event shows the capabilities of the experiment, as long as the waves are intense enough. For a more detailed study of lion roars as seen by DSP, together with a first comparison between DSP and Cluster, see Yearby et al. (2005).

\subsection{An example of coordinated crossing of the magne- topause by DSP and Cluster}

The investigation of a the physical processes by which mass and momentum are transferred through the magnetopause, from the solar wind to the magnetosphere, is one of the prime goals of both the Cluster and DSP missions. Different models have been proposed, such as the reconnection model (Sonnerup, 1980) or the Kelvin-Helmholtz instability (Pu and Kivelson, 1983; Belmont and Chanteur, 1989). Also, there is evidence for localised flux tubes, known as 


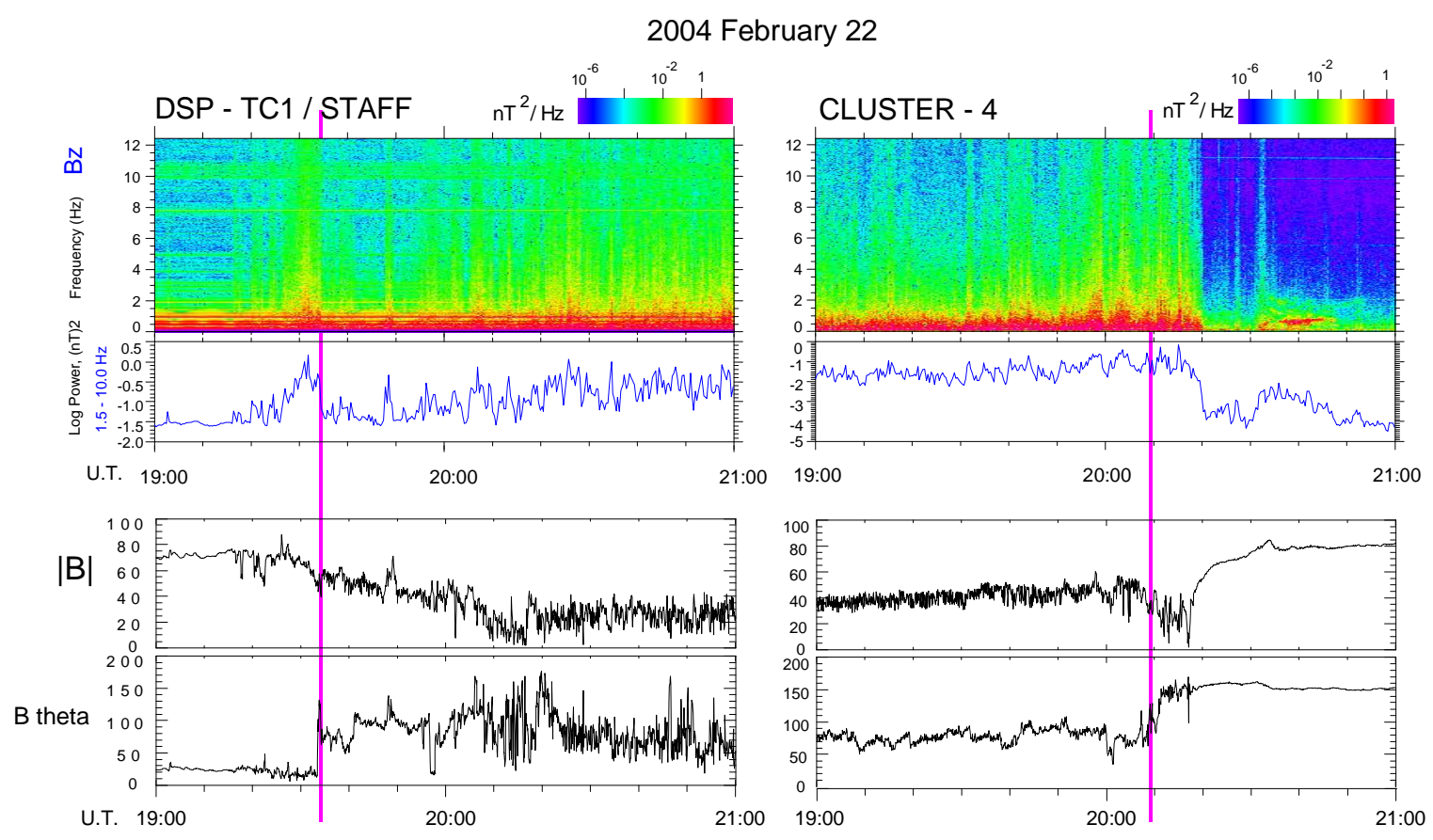

Fig. 9. Magnetopause crossing by DSP and Cluster during their outbound and inbound pass, respectively, on 22 February 2004 , indicated by a violet line. STAFF dynamic spectra data are shown in the top panel, below which are plotted the integrated spectra. At the bottom, in order to evidence the crossings, the modulus and elevation of the magnetic field from the FGM PPD are plotted (see Fig. 10 for the orbits).
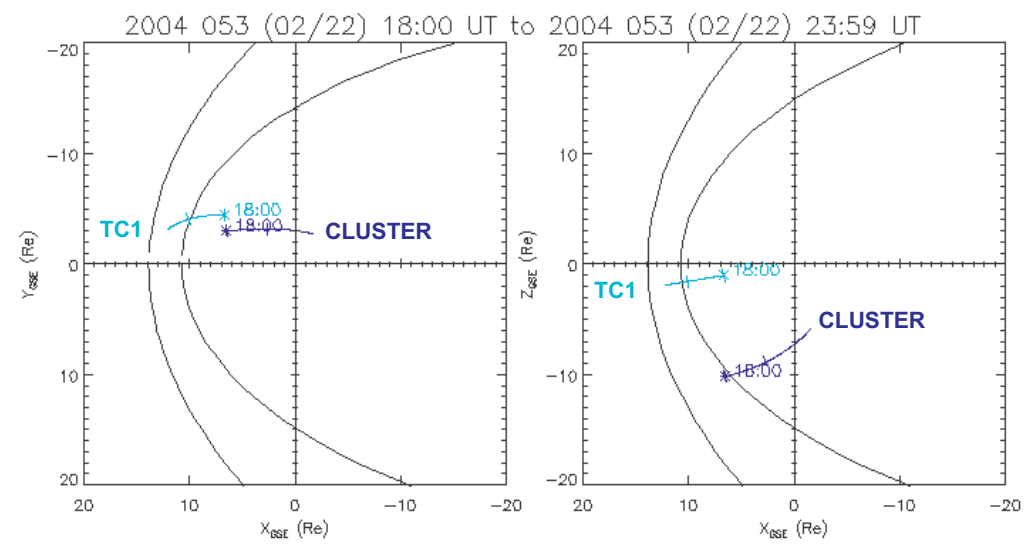

Fig. 10. Orbits of DSP TCI and Cluster for 22 February 2004 from 18:00 to 24:00 UT, including the period shown in Fig. 9. Asterisks correspond to 18:00 UT and the bars to 21:00 UT. Their orbits are in the same meridian plane, but the latitude is different at the time of the magnetopause crossing.

Flux Transfer Events (FTEs), connecting the magnetosheath to the magnetosphere (Russell and Elphic, 1979; Farrugia et al., 1987). These FTEs are viewed as remnants of reconnection events, but whether they are consequences of tearing (Bhattacharjee et al., 1999), Kelvin-Helmholtz or another instability, is still an open question. Different experimental studies have given the indication that the small-scale electromagnetic fluctuations, the amplitude of which is maximum at the magnetopause (Perraut et al., 1979; Rezeau et al., 1989; Tsurutani et al., 1989), were likely to play a significant role in these transfers, taking the place of collisions which do not exist in the medium. After some preliminary studies (Belmont et al., 1995; De Keyser et al., 1999), Belmont and Rezeau (2001) have proposed a theoretical model, which shows how the electromagnetic turbulence present in the magnetosheath can couple with the boundary. According to this paper, when incident waves, assumed to propagate on the fast magnetosonic mode, impinge on the magnetopause, they first convert to Alfvén waves. In the presence of a magnetic field rotation, these Alfvén waves can then be trapped in the boundary, thereby producing a local enhancement of the fluctuation level. The major consequence of this trapped, small-scale turbulence should be to allow microreconnection through the magnetopause, possibly distributed 
over the entire boundary (Rezeau and Belmont, 2001). The role of the waves that are observed at the magnetopause and in its vicinity is one of the prime objectives of the STAFF experiment, both on Cluster and on Double Star.

Cluster observations up to now do not permit one to choose between the different scenarios, but in fact show that the different processes are at work. Some observations by Vaivads et al. (2004) are consistent with fast, collisonless reconnection, whereas Owen et al. (2001) and Robert et al. (2002) report on Cluster observations of FTEs. Different Cluster studies gave evidence of the presence of a Kelvin-Helmholtz instability, as reported by Gustafson et al. (2001), Owen et al. (2004) and Hasegawa et al. (2004). A first Cluster magnetopause crossing case study by Rezeau et al. (2001) also shows that the magnetopause is the seat of surface waves, possibly due to this Kelvin-Helmholtz instability. Superimposed on this large-scale instability are ULF/ELF fluctuations $(0.1-\sim 100 \mathrm{~Hz})$ that, as previously observed, maximise at the magnetopause crossing, but are also present both in the boundary layer and the magnetosheath.

Thanks to the 4 Cluster spacecraft and to the use of the k-filtering method, it has been shown that the turbulence that is observed close to the magnetopause is at each frequency the superimposition of different modes at different $\mathrm{k}$, due to the Doppler effect. But contrary to the prediction, the mirror mode has been shown to be dominant, while other ULF/ELF waves are also present (Sahraoui et al., 2003; 2004; Walker et al., 2004). The first Cluster data analysis with this method, in the very close vicinity of the magnetopause, show that there is some reflection of the waves at the magnetopause (Attié, private communication). One of the questions concerning the role of the ULF turbulence on mass and momentum transfer, is to evaluate in which region this is the most efficient. The comparison between DSP and Cluster data should say whether the low latitude and the noon or subsolar region are more favourable than the high latitude, and/or morning and evening local times.

A first analysis of simultaneous Cluster and DSP data sets shows that in the time period between 21 February 2004 and 22 May 2004, there are 21 coordinated magnetopause crossings, i.e. within less than $3 \mathrm{~h}$, out of which 16 are within a 1-h time delay. The detailed comparison of this data set is left for further studies. One example is given in Fig. 9 for the magnetopause crossings of 22 February 2004 between 19:00 and 21:00 UT. DSP data are on the left and Cluster data are on the right. Only data of Cluster 4 are shown, since the STAFF data from all Cluster spacecraft are very similar, as the separation between the four Cluster spacecraft is about $200 \mathrm{~km}$ for this time period. DSP crosses the magnetopause at 19:33 UT during an outbound pass, whereas Cluster crosses it at 20:10 UT during an inbound part of its orbit. In the two top panels are plotted the STAFF MWF dynamic spectra of the $B_{z}$ component (parallel to the spin axis) from 0.1 to $12.5 \mathrm{~Hz}$ and the integrated power spectra for this component from 1.5 to $10 \mathrm{~Hz}$. The suppression of the low frequencies, eliminating strong interferences, makes the integrated powers more comparable. In the bottom two panels are plotted the magnetic field and the elevation theta angle from the FGM magnetometer Prime Parameter Data (PPD), for DSP (Carr et al., 2005) and Cluster (Balogh et al., 1997). The time of the estimated magnetopause crossing is given by a pink line. Cluster probably travels through the boundary layer between 20:10 and 20:20 UT. Figure 10 gives the orbit of Cluster and DSP TC1 in the Y, X and Z, X GSE planes from 18:00 to 24:00 UT. The asterisk is for 18:00 UT and the bar is for 21:00 UT. Whereas the spacecraft are close in local time, they are separated in latitude by $54 \mathrm{deg}$ (see Table 2 ). We have used the Sibeck model (Sibeck et al., 1991) to evaluate the magnetopause sub-solar point, i.e. its position in the Earth-Sun direction, using the spacecraft coordinates given in Table 2. The result is very similar for both crossings, 9.7 and $9.4 R_{E}$, consistent with a stable interplanetary medium for the preceding time interval. This stability of the magnetopause during the $40 \mathrm{~min}$ that separate the two crossings permits the comparison of the wave observations for these two crossings by DSP and Cluster, respectively.

Figure 11 gives the power spectra for both Cluster 1 and DSP in the magnetosheath, the closest possible to the magnetopause crossing, in order to integrate over $40 \mathrm{~s}$. The $3 \mathrm{com}-$ ponents are given, in the spacecraft reference frame, which is not far from GSE, plus the total magnetic power. Cluster spectra are in black and DSP spectra are in red. On DSP, to eliminate the strongest interferences, frequencies below $2 \mathrm{~Hz}$ have been filtered. In the $B_{x}$ and $B_{y}$ components, interferences around 8 and $10 \mathrm{~Hz}$ are clearly visible, whereas on $B_{z}$ it is clean. From these data, one can see that a comparison of DSP and Cluster $B_{z}$ components is meaningful: the spectra follow a power law, with a similar exponent of $\sim-2.6$ at both places, whereas the intensity is higher on DSP, at low latitude, by an order of magnitude.

This first result remains to be confirmed by a more systematic study of the 21 events identified and compared to a more complete study with Cluster alone.

\subsection{Examples of wave events recorded in the tail region}

From DSP-Cluster comparisons some answers may be found to the question not yet resolved concerning the processes that trigger substorms in the tail. In the 2 main groups of models, it is either the X-line formation that triggers the substorm (see, e.g. Baker et al., 1996) or the current disruption closer to the Earth that is the triggering factor (see, e.g. Lui et al., 1991; Roux et al., 1991). Timing studies should help decide between the two scenarios, with the similarity of the instruments on board Cluster and DSP, together with their respective orbits, giving a $6 R_{E}$ separation at apogee, making this comparison a priori quite suited for substorm studies.

Most of the low frequency wave events observed in the tail with DSP during summer 2004 occur during long eclipse periods. This is very favourable for the quality of the STAFFDWP wave data and the FGM magnetic field data, but no particle data are recorded during those long eclipses, thus limiting the scientific studies that can be performed during those periods. 
Table 2. Positions of Cluster and DSP TC1 on 22 February 2004 at the time they cross the magnetopause. The 4 Cluster spacecraft were separated by only $200 \mathrm{~km}$. D_Sibeck is the location of the magnetopause sub-solar point estimated with the Sibeck et al. (1991) model.

\begin{tabular}{llllllll}
\hline & $\begin{array}{l}\text { Magnetopause } \\
\text { crossing } \\
\text { time (UT) }\end{array}$ & $\mathrm{X}\left(R_{E}\right)$ & $\mathrm{Y}\left(R_{E}\right)$ & $\mathrm{Z}\left(R_{E}\right)$ & $\mathrm{R} / R_{E}$ & $\mathrm{D} \_$Sibeck $\left(R_{E}\right) *$ & Latitude (deg) \\
\hline DSP TC1 & $19: 30$ & 8.6 & 4.3 & 1.4 & 9.8 & 9.7 & 8 \\
CLUSTER & $20: 10$ & 3.7 & 3.2 & 9.4 & 10.6 & 9.4 & 62 \\
\hline
\end{tabular}

* Sibeck et al., 1991
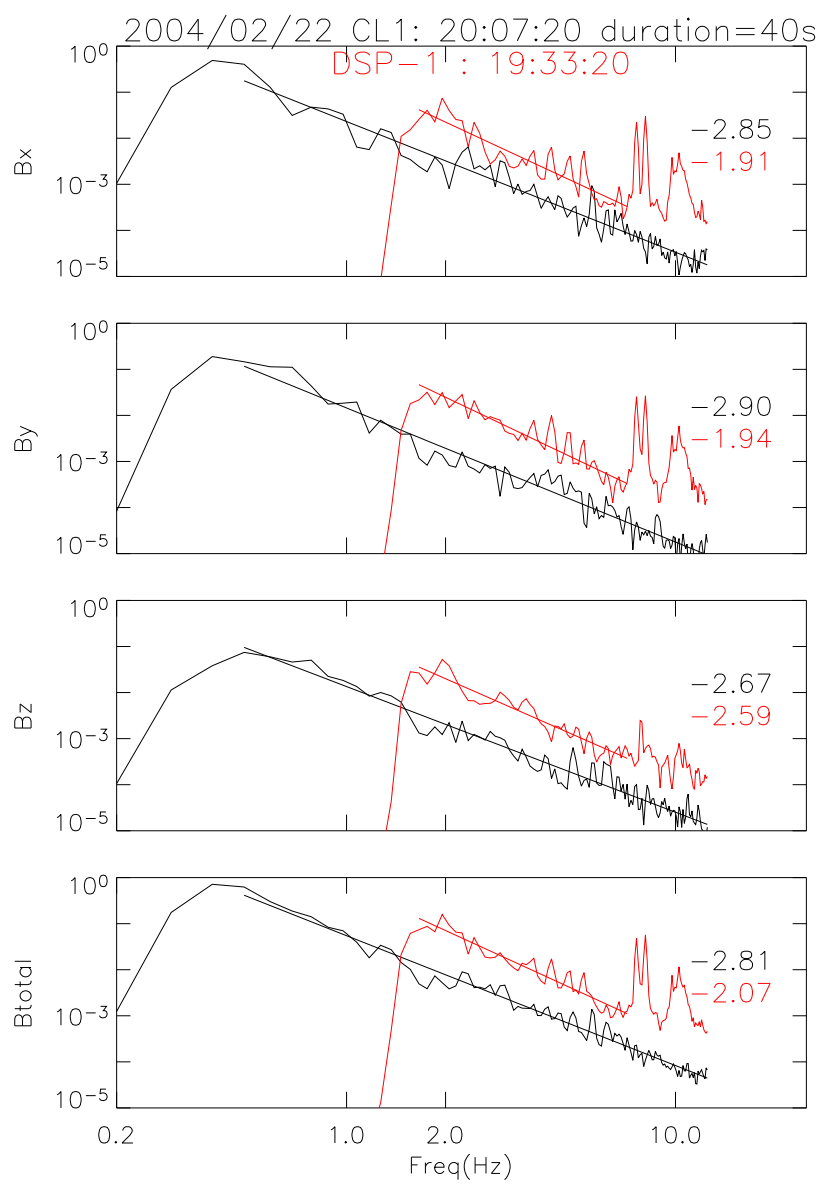

Fig. 11. Integrated power over $40 \mathrm{~s}$ of ULF waves in the magnetosheath, the closest possible to the magnetopause, for both DSP (in red) and Cluster (in black) for the 3 components in GSE. To avoid the interferences, DSP data are filtered below $2 \mathrm{~Hz}$. The power fit to a power law (nearly straight lines) is stopped at $6 \mathrm{~Hz}$, to avoid higher frequency interferences in the spin plane. Nevertheless, we will only consider the $B_{z}$ components. The exponents of the power law are shown at the right-hand side of each panel. The power law is similar for both spacecraft, but the power is stronger for DSP, at low latitude, than observed by Cluster which crosses the magnetopause at 62 deg of latitiude (see Table 2).

\subsubsection{A strong ULF wave event recorded by DSP}

On 14 September 2004, while DSP TC1 was in the tail around perigee, an example of strong ULF activity is seen that starts just at the time of a change in the magnetic field. This event occurred during a long eclipse, when only FGM and STAFF-DWP are powered-on. Thus, the 3 components of the waveform data are not noisy. From top to bottom, Fig. 12 gives the dynamic spectra of the three magnetic components of the waves in the frequency range $0.1-9 \mathrm{~Hz}$ in the satellite reference frame: $B_{x}$ and $B_{y}$ are in the spin plane, $B_{x}$ being in the Sun direction, and $B_{z}$ is parallel to the spin axis. Below the dynamic spectra the integrated power is plotted in the $1-10 \mathrm{~Hz}$ frequency range for the $B_{x}$ and $B_{z}$ components and at the very bottom the modulus of $B_{\text {perp }}$ is drawn, where the magnetic field component that is in the spin plane, is calculated from the STAFF spin signal. At the moment it is the only information that we have on the DC magnetic field, as the processing of FGM data without Sun reference pulse (we are in long eclipse) is far from being straightforward. The sudden onset of the wave activity at 15:24 UT is similar to the correlation between the ion cyclotron wave occurrence and the B field reconfigurations evidenced by Le Contel et al. (2002) and Perraut et al. (2003). The $A_{e}$ index increases at that time and Cluster sees AKR (Auroral Kilometric Radiation) around 15:30 UT, supporting that interpretation which cannot be verified with DSP, due to the lack of other measurements. It can be due also only to the penetration into the plasma sheet. Both possibilities, not exclusive, are supported by the variation of $B_{\text {perp }}$ DC.

\subsubsection{Simultaneous measurements on board Cluster and DSP}

Among possible periods for which DSP TC1 and Cluster were simultaneously in the tail during summer 2004, on 29 August, during an eclipse period for TC1 (from 05:40 to 10:00 UT), ULF wave activity was observed by both spacecraft. Data for the time interval 07:20-08:30 UT are displayed in Fig. 13, a time interval for which ULF activity was observed at both locations. The top 3 panels present DSP data and the bottom 3 panels represent Cluster 4 data. The 4 Cluster spacecraft registered similar data. The two sets of plots are similar and comprise ULF dynamic spectra in the $0.1-12 \mathrm{~Hz}$ frequency range for the $B_{z}$ component parallel to 


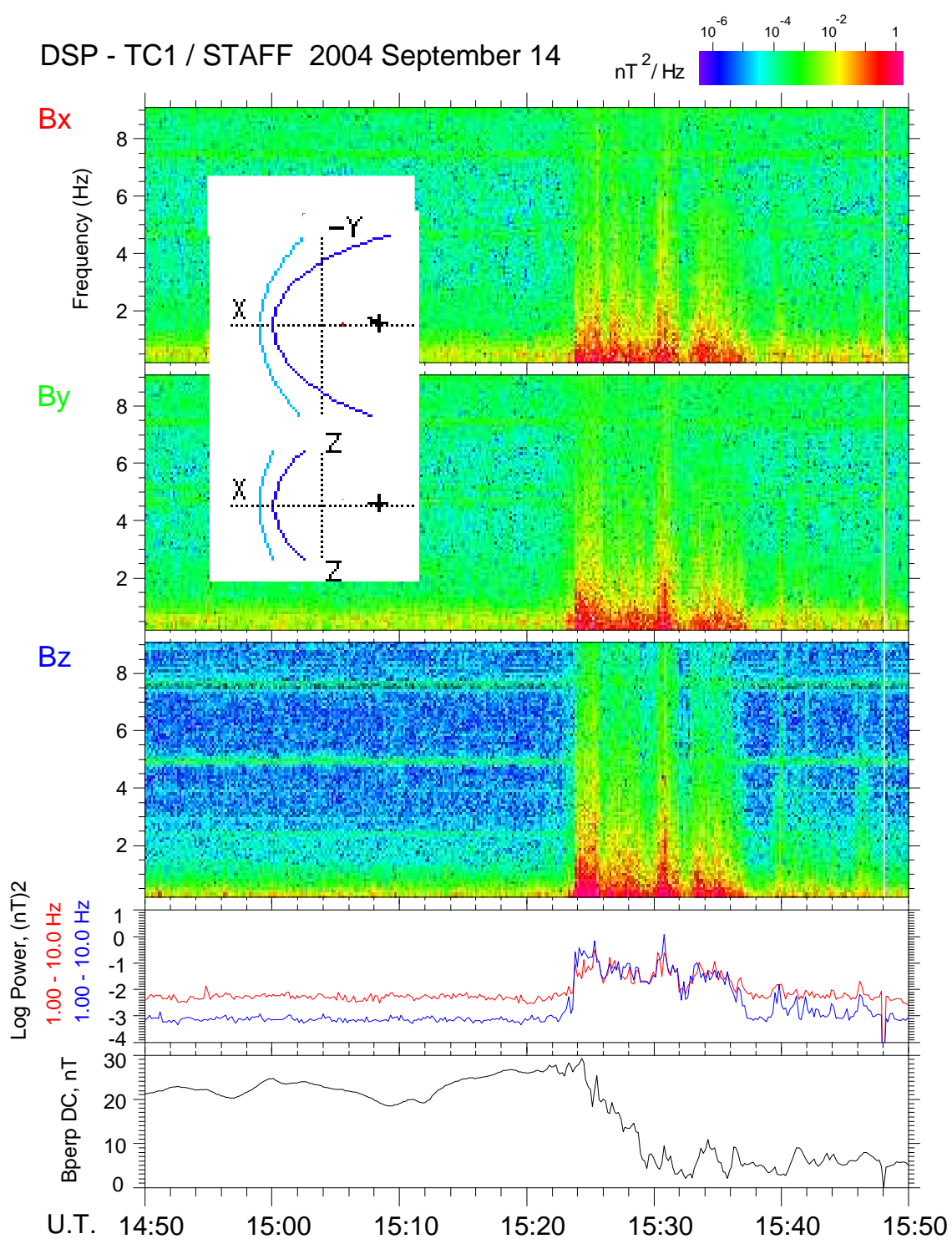

Fig. 12. DSP STAFF wave form data for an event in the tail on 14 September 2004. The start of ULF turbulence corresponds to a substorm. From top to bottom are plotted the 3 components of the dynamic spectra, the integrated power for $B_{x}$ (in red) and $B_{z}$ (in blue) and below the modulus of the magnetic field in the spin plane as inferred from the STAFF spin signal. The data are very clean, as DSP is in an eclipse for that time interval.

the spin axis, the integrated power in the $1-10 \mathrm{~Hz}$ range and at the bottom the modulus of the magnetic field in the spin plane, similar to the bottom panel of Fig. 12. From the value of $B_{\text {perp }}$ DC, one can say that for this time interval, DSP is in the plasma sheet, whereas Cluster 4 enters it at about 07:45 UT, when $B_{\text {perp }}$ DC diminishes, which is confirmed by visual inspection of the whole set of Cluster data available on the CSDS web. For DSP TC1, STAFF data are the only data available now, as explained above. It seems that for this event the ULF wave activity is rather linked to the plasma sheet encounter, but not to substorm activity, with the $A_{e}$ index being quite low and flat for the whole day. This may be consistent with the low power level of the ULF waves, more than one order of magnitude below the level of the previously reported event. Nevertheless, an event such as that on $29 \mathrm{Au}-$ gust opens the door to future work on a comparison between DSP and Cluster data in view of a better understanding of substorm related and triggering processes.

\section{Summary and conclusions}

We have shown that despite the fact that the STAFF axial boom didn't deploy on DSP TC1, the STAFF-DWP experiment described in this paper works well in itself and can give scientifically significant results in mainly two different conditions: either the natural wave events are intense and stronger than the interferences, or the spacecraft is in eclipse, which happens near apogee in the tail. 

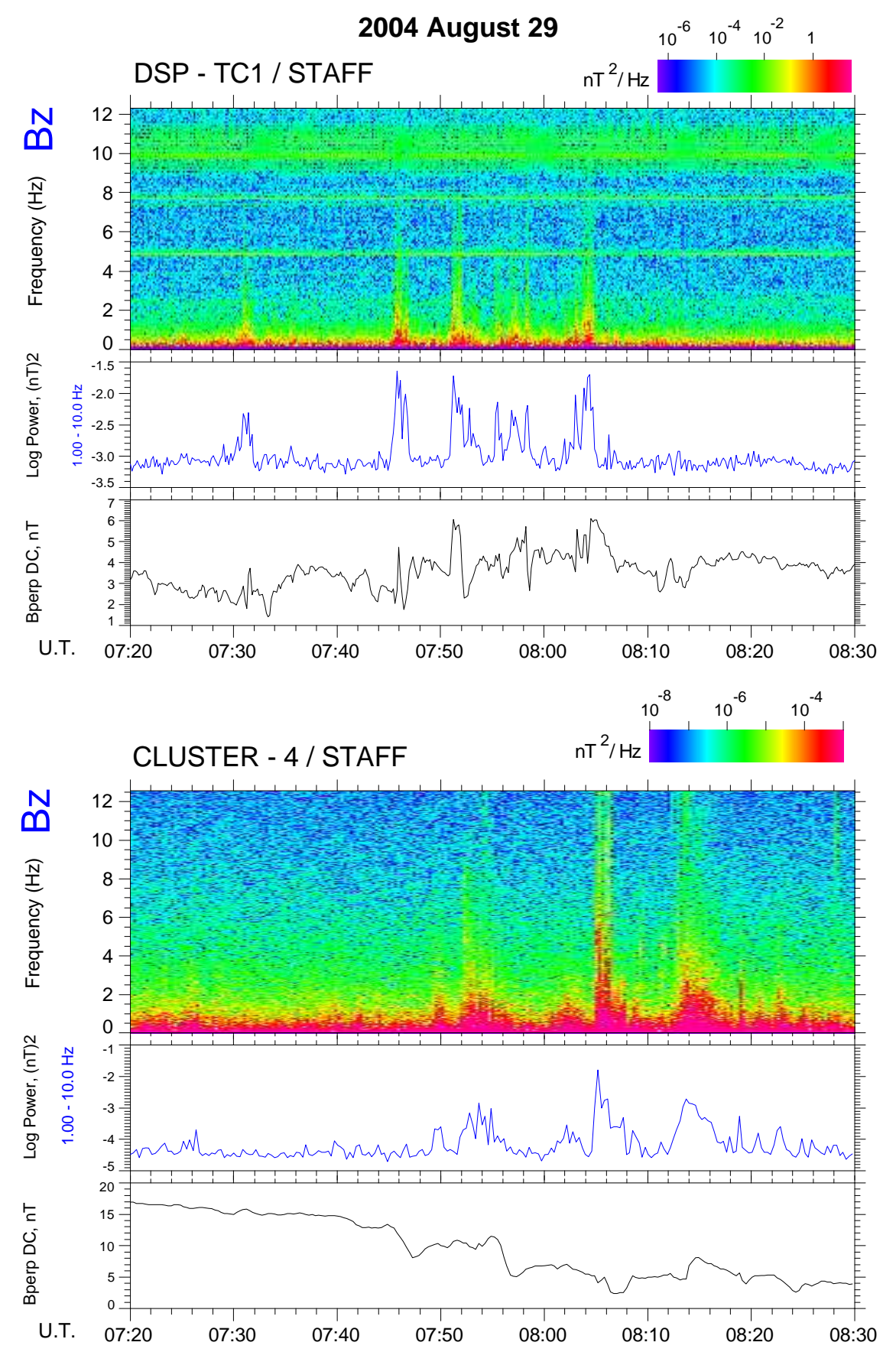

Fig. 13. Simultaneous wave observations by Cluster and DSP in the tail for 29 August 2004. For both spacecraft are given the $B_{z}$ dynamic spectra, integrated power and $B_{\text {perp }}$ (see Fig. 12). DSP was in the plasma sheet whereas Cluster enters it, coming from the lobes, at about 07:45 UT. This is a quiet day, with no substorm activity.

Generally the search coil component that is along the $y$ spacecraft axis $S C_{y}$ is less perturbed, and interferences are less numerous and intense above $100 \mathrm{~Hz}$. The global level of interferences varies with time, depending, on the one hand, on the spacecraft and the payload operation modes and, on the other hand, on the spacecraft solar aspect angle. When the wave events are strong, all three components can be used to determine all wave properties such as polarisation, oth- erwise the best one (less noisy) component is used. There is less interference and thus less background noise in the eclipses, when only STAFF-DWP and FGM are powered-on. Putting all this together, it means that one can make use of STAFF-DSP data for most of the wave events above $100 \mathrm{~Hz}$, for chorus and strong lion roar events in the magnetosheath, and in the case of ULF waves, those that are generally broad-band and particularly intense at boundary crossings 
(magnetopause and bow shock), and are often above the noise level in the magnetosheath. For the night-side, the upto-now observed waves are less intense, but $\mathrm{TC} 1$ experiences long eclipses in the tail during which STAFF-DWP data are quite clean; unfortunately, these periods scientifically suffer from the absence of particle measurements.

The preliminary results presented here, besides providing an overview of the different kinds of waves that are present on the dayside orbit of DSP TC1, give the first steps of future work on items that are of primary interest for DSP and for comparison between DSP and Cluster.

The possibility of comparing intensity and power law of ULF waves in the vicinity of the magnetopause, at different latitudes, should help to identify the role of this strong ULF turbulence in the transfer of mass and momentum from the solar wind to the magnetosphere. In the first case study presented here, the power law is the same, while the intensity is stronger on DSP at low latitude. This result needs to be explored further in light of other magnetopause crossings before drawing final conclusions as to whether it is a unique or general result. Correlation of DSP and Cluster data in the tail, due to the similarity of the instruments and the separation of some 5 Earth radii at their apogees also opens doors to possible improvement in the understanding of the physical processes responsible for substorm onset. The first example found of simultaneous wave measurements in the tail and given here, shows that such a comparison is possible; unfortunately, this event is not substorm associated. Further analysis of other events is to be carried out.

Acknowledgements. The refurbishment, modifications, tests and integrations on TC1 of the Cluster spare models of STAFF and DWP was funded by the European Space Agency. The operations and data analysis are supported in France by a CNES grant and in the UK by a PPARC grant. ESA/ESTEC, Astrium, Magson, CSSAR and CAST teams are thanked for their invaluable help. Cluster and DSP FGM teams are thanked for providing Prime Parameter Data that are used in this study. Both referees are thanked for their constructive comments.

Topical Editor T. Pulkkinen thanks J. S. Pickett and another referee for their help in evaluating this paper.

\section{References}

Baker, D. N., Pulkinen, T. I., Angelopoulos, V., Baumjohann, W., and McPherron, R. L.: Neutral line model of substorms: Past results and present view, J. Geophys. Res., 101, 12975-13 010, 1996.

Balogh, A., Dunlop, M. W., Cowley, S. W. H, Southwood, D. J., Thomlinson, J. G., Glassmeier, K.-H., Musmann, G., Lühr, H., Buchert, S., Acuña, M. H., Fairfield, D. H., Slavin, J. A., Riedler, W., Schwingenschuh, K., and Kivelson, M. G.: The Cluster Magnetic field Investigation, Space Science Reviews, 79 (1-2), 107136, 1997.

Baumjohann, W., Treumann, R.A., Georgescu, E., Haerendel, G., Fornacon, K.-H., and Auster, U.: Waveform and packet structure of lion roars, Ann. Geophys., 17, 1528-1534, 1999.
Belmont, G. and Chanteur, G.: Advances in magnetopause KelvinHelmholtz instability studies, Physica Scripta, 40, 124-128, 1989.

Belmont, G. and Rezeau, L.: Magnetopause reconnection induced by magnetosheath Hall-MHD fluctuations, J. Geophys. Res. 106, 10 751-10 760, 2001.

Belmont, G., Rezeau, L., and Reberac, F.: Resonant amplification of magnetosheath MHD fluctuations at the magnetopause, Geophys. Res. Lett., 22, 295-298, 1995.

Bhattacharjee, A., Ma, Z. W., and Wang, X.: Impulsive reconnection dynamics in collisionless laboratory and space plasmas, J. Geophys. Res., 104, 14 543-14 555, 1999.

Carr, C., Brown, P., Zhang, T. L., Gloag, J., Horbury, T.,Lucek, E., Magnes, W., O’Brien, H., Oddy, T., Auster, U., Austin, P., Aydogar, O., Balogh, A., Baumjohann, W., Beek, T., Eichelberger, H., Fornacon, K.-H., Georgescu, E., Glassmeier, K.-H., Ludlam, M., Nakamura, R., and Richter, I.: The Double Star magnetic field investigation: instrumentation design, performance and highlights of the first year's observations, Ann. Geophys. 23, 2713-2732, 2005.

Cornilleau-Wehrlin, N., Chauveau, P., Louis, S., Meyer, A., Nappa, J. M., Perraut, S., Rezeau, L., Robert, P., Roux, A., de Villedary, C., de Conchy Y., Friel, L., Harvey, C. C., Hubert, D., Lacombe, C., Manning, R., Wouters, F., Lefeuvre, F., Parrot, M., Pinçon, J. L., Poirier, B., Kofman, W., and Louarn, Ph.: The CLUSTER Spatio-Temporal Analysis of Field Fluctuations (STAFF) Experiment, Space Sci. Rev., 79, 107-136, 1997.

Cornilleau-Wehrlin, N., Chanteur, G., Perraut, S., Rezeau, L., Robert, P., Roux, A., de Villedary, C., Canu, P., Maksimovic, M., de Conchy, Y., Hubert, D., Lacombe, C., Lefeuvre, F., Parrot, M., Pinçon, J. L., Décréau, P. M. E., Harvey, C. C., Louarn, Ph., Santolík, O., Alleyne, H. St. C., Roth, M., and STAFF team: First results obtained by the Cluster STAFF experiment, Ann. Geophys., 21, 437-456, 2003.

De Keyser, J., Roth, M., Reberac, F., Rezeau, L., and Belmont, G.: Resonant amplification of MHD waves in realistic subsolar magnetopause configurations, J. Geophys. Res., 104, 23992409, 1999.

Fazakerley, A. N., Carter, P. J., Watson, G., Spencer, A., Sun, Y. Q., Coker, J., Coker, P., Kataria, D. O., Fontaine, D., Liu, Z. X., Gilbert, L., He, L., Lahiff, A. D., Mihaljčić, B., Szita, S., Taylor, M. G. G. T., Wilson, R. J., Dedieu, M., and Schwartz, S. J.: The Double Star plasma electron and current experiment, Ann. Geophys., 23, 2733-2756, 2005.

Farrugia, C. J., Elphic, R. C., Southwood, D. J., and Cowley, S. W. H.: Field and flow perturbations outside the reconnection field line region in flux transfer events: theory, Planet. Space. Sci., 35, 227-240, 1987.

Gustafsson, G., André, M., Carozzi, T., Eriksson, A. I., Fälthammar, C.-G., Grard, R., Holmgren, G., Holtet, J. A., Ivchenko, N., Karlsson, T., Khotyaintsev, Y., Klimov, S., Laakso, H., Lindqvist, P.-A., Lybekk, B., Marklund, G., Mozer, F., Mursula, K., Pedersen, A., Popielawska, B., Savin, S., Stasiewicz, K., Tanskanen, P., Vaivads, A., and Wahlund, J.-E.: First results of electric field and density observations by Cluster EFW based on initial months of operation, Ann. Geophys., 19, 1219-1240, 2001.

Hasegawa, H., Fujimoto, M., Phan, T. D., Rème, H., Balogh, A., Dunlop, M. W., Hashimoto, C., and TanDokoro, R.: Transport of solar wind into Earth's magnetosphere through rolled-up KelvinHelmholtz vortices, Nature, 430, 755-758, 2004. 
Johnstone, A. D., Alsop, C., Burge, S., Carter, P. J., Coates, A. J., Coker, A. J., Fazakerley, A. N., Grande, M., Gowen, R. A., Gurgiolo, C., Hancock, B. K., Narheim, B., Preece, A., Sheather, P. H., Winningham, J. D., and Woodliffe, R. D.: Peace: A Plasma Electron and Current Experiment, Space Sci. Rev., 79, 351-398, 1997.

Le Contel, O., Roux, A., Perraut, S., Pellat, R., Robert, P., Chanteur G., Fontaine, D., Cornilleau-Wehrlin, N., Sauvaud, J.-A., Cully, C., Parks, G., Chua, D., André, M., Balogh, A., Fazakerley, A., Rème, H., Nagai, T., Mukai, T., Hayakawa, H., Matsuoka, A., Andserson, R., and Matsumoto, H.: Role of the Parallel Current Instability during Substorms: Theory and Observations, 6th International Conference on Substorm (ICS-6), 25-29 mars 2002, University of Washington, Seattle, USA, 326-333, 2002.

Lui, A. T. Y., Chang, C.-L., Mankofsky, A., Wong, H.-K., and Winske, D.: A cross-field current instability for substorm expansions, J. Geophys. Res., 96, 11 389-11 407, 1991.

Maksimovic, M., Harvey, C. C., Santolík, O., Lacombe, C., de Conchy, Y., Hubert, D., Pantellini, F., Cornilleau-Werhlin, N., Dandouras, I., Lucek, E. A., and Balogh, A.: Polarisation and propagation of lion roars in the dusk sidemagnetosheath, Ann. Geophys., 19, 1429-1438, 2001.

Owen, C. J., Fazakerley, A. N., Carter, P. J., Coates, A. J., Krauklis, I. C., Szita, S., Taylor, M. G. G. T., Travnicek, P., Watson, G., Wilson, R. J., Balogh, A., and Dunlop, M. W.: Cluster PEACE observations of electrons during magnetospheric flux transfer events, Ann. Geophys., 19, 1509-1522, 2001.

Owen, C. J., Taylor, M. G. G. T., Krauklis, I. C., Fazakerley, A. N., Dunlop, M. W., and Bosqued, J.-M.: Cluster observations of surface waves on the dawn flank magnetopause, Ann. Geophys., 22, 971-983, 2004.

Parrot, M., Santolík, O., Cornilleau-Wehrlin, N., Maksimovic, M., and Harvey, C. C: Source location of chorus emissions observed by Cluster, Ann. Geophys., 21, 473-480, 2003a.

Parrot, M., Santolík, O., Cornilleau-Wehrlin, N., Maksimovic, M., and Harvey, C. C.: Magnetospherically reflected chorus waves revealed by ray tracing with Cluster data, Ann. Geophys., 21, 1111-1120, 2003b.

Pedersen, A., Cornilleau-Wehrlin, N., de la Porte, B., Roux, A., Bouabdellah, A., Décréau, P. M. E., Lefeuvre, F., Sené, F. X., Gurnett, D., Huff, R., Gustafsson, G., Holmgren, G., Woolliscroft, L. J. C., Thompson, J. A., and Davies, P. H. N.: The Wave Experiment Consortium (WEC), Space Sci. Rev., 79, 93-106, 1997.

Perraut, S., Gendrin, R., Robert, P., and Roux, A.: Magnetic pulsations observed onboard GEOS 2 in the ULF range during multiple magnetopause crossings, in: Proceedings of Magnetospheric Boundary Layer Conference, Alpbach, June 1979, ESA/SP-148, 113-122, 1979.

Perraut, S., Le Contel, O., Roux, A., Parks, G., Chua, D., Hoshino, M., Mukai, T., and Nagai, T.: Substorm expansion phase: Observations from Geotail, Polar and IMAGE network, J. Geophys. Res., 108, doi:10.1029/2002JA009376, 2003.

$\mathrm{Pu}$, Z. Y. and Kivelson, M. G.: Kelvin-Helmholtz instability at the magnetopause: solution for compressible plasmas, J. Geophys.Res., 88, 841-852, 1983.

Rezeau, L., Morane, A., Perraut, S., Roux, A., and Schmidt, R.: Characterization of Alfvenic fluctuations in the magnetopause boundary layer, J. Geophys. Res., 94, 101-110, 1989.

Rezeau, L. and Belmont, G.: Magnetic turbulence at the magnetopause, a key problem for understanding the solar wind/ magnetosphere exchanges, Space Sci. Rev, 95, 427-441, 2001.
Rezeau, L., Sahraoui, F., d'Humières, E., Belmont, G., CornilleauWehrlin, N., Mellul, L., Lucek, E., Robert, P., Décréau, P., and Canu, P.: A case study of low-frequency waves at the magnetopause, Ann. Geophys., 19, 1463-1470, 2001.

Robert, P., Roux, A., Fontaine, D., Canu, P., Le Contel, O., Perraut S., Cornilleau-Wehrlin, N., Dunlop, M. W., Balogh, A., Glassmeier, K.-H., Bosqued, J.-M., Fazakerley, A., Behlke, R., and Décréau, P.: Cluster observations of a flux transfer event (FTE), in: Cospar, Plenary Meeting, 2002cosp.meetE2676R, 2002.

Roux, A., Perraut, S., Robert, P., Morane, A., Pedersen, A., Korth, A., Kremser, G., Aparicio, B., Rogers, D., and Pellinen, R.: Plasmasheet instability related to the westward travelling surge, J. Geophys.Res., 96, 17 697-17 714, 1991.

Russell, C. T. and Elphic, R. C.: ISEE observations of flux transfer events at the dayside magnetopause, Geophys. Res. Lett., 6, 3336, 1979.

Russell, C. T., Holzer, R. E., and Smith, E. J.: OGO 3 observations of ELF noise in the magnetosphere, 2, The nature of the equatorial noise, J. Geophys. Res., 73, 755-768, 1970.

Sahraoui, F., Pinçon, J. L., Belmont, G., Rezeau, L., CornilleauWehrlin, N., Robert, P., Mellul, L., Bosqued, J.-M., Balogh, A., Canu, P., and Chanteur, G.: ULF wave identification in the magnetosheath: k-filtering technique applied to Cluster II data, J. Geophys. Res., 108, 1335-1352, 2003.

Sahraoui, F., Belmont, G., Pinçon, J.-L., Rezeau, L., Balogh, A., Robert, P., and Cornilleau-Wehrlin, N.: Magnetic turbulent spectra in the magnetosheath: new insights, Ann. Geophys., 22, 2283-2288, 2004.

Santolík, O.: Propagation Analysis of STAFF-SA Data with Coherency Tests (A User's Guide to PRASSADCO), LPCE/NTS/073.D, Lab. Phys. Chimie Environ./CNRS, Orléans, France, 2003.

Santolík, O. and Parrot, M.: Propagation analysis of electromagnetic waves between the helium and proton gyro-frequencies in the low-altitude auroral zone, J. Geophys. Res., 103, $20469-$ $20480,1998$.

Santolík O. and Parrot, M.: Case studies on wave propagation and polarization of ELF emissions observed by Freja around the local proton gyro-frequency, J. Geophys. Res., 104, 2459-2476, 1999.

Santolík, O., Lefeuvre, F., Parrot, M., and Rauch, J. L.: Complete wave-vector directions of electromagnetic emissions: Applications to INTERBALL-2 measurements in the night-side auroral zone, J. Geophys. Res., 106, 13 191-13 201, 2001.

Santolík, O., Pickett, J. S., Gurnett, D. A., Maksimovic, M., and Cornilleau-Wehrlin, N.: Spatio-temporal variability and propagation of equatorial noise observed by Cluster, J. Geophys. Res., 107, No. A12, 1495, doi:10.1029/2001JA009159, 2002.

Santolík, O., Macusova, E., Yearby, K., Cornilleau-Wehrlin, N., and Alleyne, H. St. C.: Radial variation of whistler-mode chorus: first results from the STAFF instrument on board the Double Star TC-1, Ann. Geophys., 23, 2937-2942, 2005.

Sibeck, D. G. , Lopez, R. E., and Roelof, E. C.: Solar wind control of the magnetopause shape, location and motion, J. Geophys. Res., 96, 5489-5495, 1991.

Smith, E. J. and Tsurutani, B. T.: Magnetosheath lion roars, J. Geophys. Res., 81, 2261-2266, 1976.

Sonnerup, B. U. Ö.: Theory of low latitude boundary layer, J. Geophys. Res., 85, 2017-2026, 1980.

Tsurutani, B. T., Smith, E. J., Anderson, R. R., Ogilvie, K. W., Scudder, J. D., Baker, D. N., and Bame, S. J.: Lion roars and nonoscillatory drift mirror waves in the magnetosheath, J. Geophys. Res., 87, 6060-6072, 1982. 
Tsurutani, B. T., Brinca, A. L., Smith, E. J., Okida, R. T., Anderson, R. R., and Eastman, T. E.: A statistical study of ELF/VLF plasma waves at the magnetopause, J. Geophys. Res., 94, 1270-1280, 1989.

Vaivads, A., Khotyaintsev, Y., André, M., Retino, A., Buchert, S. C., Rogers, B. N., Décréau, P., Paschmann, G., and Phan, T.: Structure of the magnetic reconnection diffusion region from fourspacecraft observations, Phys. Rev. Lett., 93, 105001-1-1050014, 2004

Walker, S. N., Sahraoui, F., Balikhin, M. A., Belmont, G., Pinçon, J. L., Rezeau, L., Alleyne H. St. C., Cornilleau-Wehrlin, N., and André, M.: A comparison of wave mode identification techniques, Ann. Geophys., 22, 3021-3032, 2004.
Woolliscroft, L. J. C., Alleyne, H. St. C., Dunford, C. M., Sumner, A., Thompson, J. A., Walker, S. N., Yearby, K. H., Buckley, A., Chapman, S., Gough, M. P., and the DWP co-investigators: The digital wave processing experiment on Cluster, Space Sci. Rev., 79, 209-231, 1997.

Yearby, K. H., Alleyne, H. St C., Cornilleau-Wehrlin, N., Santolík, O., Balikhin, M. A., Walker, S. N., Fazakerley, A., and Lahiff, A.: Observations of lion roars in the magnetosheath by the STAFF/DWP experiment on the Double Star TC1 spacecraft, Ann. Geophys., 23, 2861-2866, 2005.

Zhang, Y., Matsumoto, H., and Kojima, H.: Lion roars in the magnetosheath: The Geotail observations, J. Geophys. Res., 103, 4615-4626, 1998. 